\title{
Optimization of self-nanoemulsifying formulations for weakly basic lipophilic drugs: role of acidification and experimental design
}

\author{
Ahmad Abdul-Wahhab Shahba ${ }^{1 *}$, Kazi Mohsin ${ }^{1}$, Fars Kaed Alanazi ${ }^{1}$, Sayed Ibrahim \\ Abdel-Rahman ${ }^{2}$
}

\begin{abstract}
${ }^{1}$ Kayyali Chair for Pharmaceutical Industries, Department of Pharmaceutics, College of Pharmacy, King Saud University, Riyadh, Kingdom of Saudi Arabia, ${ }^{2}$ Department of Industrial Pharmacy, College of Pharmacy, Assiut University, Assiut, Egypt
\end{abstract}

\begin{abstract}
Formulators face great challenges in adopting systematic approaches for designing self-nanoemulsifying formulations (SNEFs) for different drug categories. In this study, we aimed to build-up an advanced SNEF development framework for weakly basic lipophilic drugs, such as cinnarizine (CN). First, the influence of formulation acidification on CN solubility was investigated. Second, formulation self-emulsification in media with different $\mathrm{pH}$ was assessed. Experimentally designed phase diagrams were also utilized for advanced optimization of CN-SNEF. Finally, the optimized formulation was examined using cross polarizing light microscopy for the presence of liquid crystals. $\mathrm{CN}$ solubility was significantly enhanced upon external and internal acidification. Among the various fatty acids, oleic acid-based formulations showed superior self-emulsification in all the tested media. Surprisingly, formulation turbidity and droplet size significantly decreased upon equilibration with $\mathrm{CN}$. The design was validated using oleic acid/ Imwitor308/Cremophor El (25/25/50), which showed excellent self-nanoemulsification, 43-nm droplet size (for $\mathrm{CN}$-equilibrated formulations), and $88 \mathrm{mg} / \mathrm{g} \mathrm{CN}$ solubility. In contrast to $\mathrm{CN}$-free formulations, $\mathrm{CN}$-loaded SNEF presented lamellar liquid crystals upon 50\% aqueous dilution. These findings confirmed that CN-SNEF efficiency was greatly enhanced upon drug incorporation. The adopted strategy offers fast and accurate development of SNEFs and could be extrapolated for other weakly basic lipophilic drugs.
\end{abstract}

Uniterms: Self-nanoemulsifying formulations/solubility. Cinnarizine/lipophilic drugs. Acidification/ experimental design. Solubility enhancement.

\section{INTRODUCTION}

As a result of modern drug discovery practices, there has been a consistent rise in the number of newly discovered chemical entities that are considered poorly water-soluble drugs (PWSDs). Owing to their poor dissolution, these PWSDs often present low and erratic bioavailabilities. Pharmaceutical experts are therefore facing great challenges in formulating these entities into oral dosage forms with adequate bioavailability (Dahan, Hoffman, 2008). Among the various lipid-based formulations, self-nanoemulsifying formulations (SNEFs) represent one of the most promising candidates in terms of enhancing the in-vivo performance of orally administered PWSD (Bahloul et al., 2015). Compared with other drug

*Correspondence: A. A.-W. Shahba. Kayyali Chair for Pharmaceutical Industries. Department of Pharmaceutics, PO BOX-2457. College of Pharmacy, King Saud University. Riyadh - 11451, Kingdom of Saudi Arabia. Tel: +966114676228, ext. 108 / Fax: +966114676295. E-mail: shahba@ksu.edu.sa delivery systems, SNEFs offer great advantages, including ease of manufacture and scaling-up, improved physical stability, and maximized drug entrapment capacity. Upon introduction to physiological media, no dissolution step would be required owing to the formation of a nanodroplet size emulsion. This facilitates a higher rate and extent of absorption and therefore high and reproducible bioavailability values (Balakumar et al., 2013; Gupta, Kesarla, Omri, 2013).

Current development approaches in the SNEF area are mostly empirical and consume large amounts of time and money (Dahan, Hoffman, 2008; Bahloul et al., 2015). SNEFs are commonly developed using the "trial and error approach" which involves changing one parameter at a time or the conventional "ternary phase diagrams" technique. These two methods require several experiments, hence resulting in high cost and long development periods (Bahloul, Lassoued, Sfar, 2014). In addition, some formulations might be mischaracterized 
owing to inadequate testing conditions, as further mentioned in the "self-emulsification assessment section" of the current study. Many other limitations still restrict the potential usage of SNEFs, including the lack of predictive in-vitro tests, insufficient in-vivo drug precipitation studies, and lack of in vitro-in vivo correlations (IVIVC) (Bahloul et al., 2015). SNEF optimization for each drug is not an easy process. Only very specific excipient combinations will produce efficient self-nanoemulsifying systems. This could be confirmed by the vast amount of research performed in this area leading to only limited numbers of SNEF products in the pharmaceutical market (Gursoy, Benita, 2004; Elnaggar, El-Massik, Abdallah, 2009; Bahloul et al., 2015).

Therefore, regarding in-vitro prospects, there is a need for an advanced approach to accelerate the design, characterization, and optimization of SNEFs and adopt a formulation design platform that suits similar drug models (Bahloul et al., 2015).

The aim of the current study is to build-up an advanced SNEF design framework for weakly basic lipophilic drugs. Cinnarizine (CN), a highly lipophilic compound $(\log P=5.8)$ (Loftsson, Hreinsdóttir, Másson, 2005), was selected as the model drug for the current study. $\mathrm{CN}$ is a weak base with $\mathrm{P} k_{\mathrm{a} 1}=1.94$ and $\mathrm{P} k_{\mathrm{a} 2}=$ 7.47 (Tokumura et al., 1987). It shows a $\mathrm{pH}$-dependent solubility that is $0.29 \mathrm{mg} / \mathrm{mL}$ at $\mathrm{pH} 2,0.017 \mathrm{mg} / \mathrm{mL}$ at $\mathrm{pH} 5$, and $0.002 \mathrm{mg} / \mathrm{mL}$ at $\mathrm{pH} 6.5$ (Gu et al., 2005; Raghuvanshi, Pathak, 2014). Therefore, it is vital to consider the influence of formulation acidity and $\mathrm{pH}$ variation during the design of CN-SNEF (Shahba, Mohsin, Alanazi, 2012a). In the current study, we aim to bridge the gaps regarding critical characterization issues, explore the role of formulation acidification, and utilize the experimental design for a time-effective and accurate optimization of SNEFs for weakly basic lipophilic drugs.

\section{MATERIAL AND METHODS}

\section{Material}

Miglyol 810 (M810, medium chain triglycerides), Miglyol 812 (M812, medium chain triglycerides), Imwitor 308 (I308, medium chain monoglycerides), and Imwitor 988 (I988, medium chain mono/diglycerides) were kindly supplied by Sasol GmbH, Germany. Oleic acid (OL, long chain fatty acid C18) and Tween 80 (T80) were obtained from Avonchem, UK. Tween 85 (T85) was purchased from Merck-Schuchardt OHG, Germany. Tween 20 (T20) was purchased from BDH, UK. Cremophor EL (Cr-El) and Cremophor RH40 (Cr-RH40) were supplied by BASF, Germany. CremerAc Capric acid (C10) 98/100 and Cremer AC distilled coconut oil fatty acids (COFA) were kindly supplied by Cremer Oleo $\mathrm{GmbH} \& \mathrm{Co}$. KG, Germany. Caprylic acid (C8) was purchased from Wuji Xinhui Chemical Co. Ltd, China. Sefsol 218 (S218), HCO-30, and HCO-60 were kindly provided by Nikko Chemicals, Japan. Lauroglycol 90 and Capmul PG-12 were kindly supplied by Gattefosse, France and Abitec, USA, respectively. CN was supplied by FDC Limited, India.

\section{Equilibrium solubility studies}

The equilibrium CN solubility in diverse formulations was determined according to previously reported studies (Baka, Comer, Takács-Novák, 2008) with some modifications. After at least a three-day equilibration period, samples were withdrawn, centrifuged, and assayed using ultra-performance liquid chromatography (UPLC) (Abdel-Hamid et al., 2012; Shahba, Mohsin, Alanazi, 2012a).

\section{Self-emulsification assessment}

A previously reported (Kommuru et al., 2001; Shahba, Mohsin, Alanazi, 2012b) visual test, used to assess self-emulsification efficiency, was modified and adopted for the current study. In accordance with routine practice, formulation dispersion in water was utilized as a fast and general tool to assess formulation self-emulsification efficiency. However, in the current study, it was proven that "formulation dispersion in water" was not sufficient alone because some formulations may show variable emulsification behaviors at different $\mathrm{pH}$.

To assess such formulations accurately, drugequilibrated formulations were dispersed under the following conditions:

Primarily, formulations were subjected to $1: 400$ aqueous dilution in a $50.0 \mathrm{~mL}$ glass beaker, and the contents were gently mixed ( $\sim 500 \mathrm{rpm})$ using a magnetic stirrer (Nekkanti et al., 2010; Shahba, Mohsin, Alanazi, $2012 b)$. Alternatively, formulations (20-30 mg) were diluted with $50.0 \mathrm{~mL}$ of $0.1 \mathrm{~N} \mathrm{HCl}(\mathrm{pH} 1.2)$ in order to mimic gastric $\mathrm{pH}$. The contents were then gently mixed as previously described. Finally, $25.0 \mathrm{~mL}$ of $\approx 120 \mathrm{mM}$ tribasic sodium phosphate solution was added to the latter media to reach a $\mathrm{pH}$ of 6.8 , mimicking intestinal $\mathrm{pH}$. The contents were again gently mixed as previously described. This step was very critical, particularly for weakly basic drugs whose behavior varies greatly depending on media $\mathrm{pH}$. 
The formulations were evaluated on the basis of performance indicator tools, such as excipient miscibility, spontaneity, and homogeneity/dispersibility (Shahba, Mohsin, Alanazi, 2012b).

\section{Optical density}

For further exploration of assessment results, the optical density (OD) of selected diluted formulations were examined at $600.0 \mathrm{~nm}$ using an UV-visible spectrophotometer (UVD-3200, Labomed Inc., USA) (Date, Nagarsenker, 2007; Thakkar et al., 2011). Prior to OD measurement, drug free and/or drug equilibrated formulations were subjected to 1:400 aqueous dilutions in a $50.0 \mathrm{~mL}$ glass beaker, and the contents were gently mixed using a magnetic stirrer ( $\sim 500 \mathrm{rpm})$ (Nekkanti et al., 2010; Shahba, Mohsin, Alanazi, 2012b). Formulation clarity was categorized according to the following $\mathrm{OD}_{600}$ ranges: transparent: $\mathrm{OD}_{600}=0.00-0.05$, bluish: $\mathrm{OD}_{600}=0.05-0.1$, turbid: $\mathrm{OD}_{600}=0.1-0.3$, and milky: $\mathrm{OD}_{600}>0.3$ (Shahba, Mohsin, Alanazi, 2012b).

\section{Droplet size analysis}

The average droplet size of the diluted SNEF was examined using a Zetasizer Nano ZS (Malvern, UK). The formulations were diluted in distilled water at a ratio of $1: 1000 \mathrm{v} / \mathrm{v}$ and mixed for $1 \mathrm{~min}$ prior to examination (Kommuru et al., 2001; Atef, Belmonte, 2008).

\section{Experimentally designed phase diagrams}

Phase diagram studies often require large numbers of sample preparations, thereby requiring extensive time. In the current study, all phase diagrams were constructed using advanced experimental design in order to reduce the number of experiments, save time, and obtain a comprehensive analysis of the data. Design Expert ${ }^{\circledR}$ (version 9, Stat-Ease, Inc., USA) was used to construct the D-optimal mixture design (Mukherjee, Plakogiannis, 2010) of CN-SNEFs. The mixture study included three components: the oil portion (represented by free fatty acid, A), the co-surfactant portion (represented by I308, B), and the surfactant portion (represented by $\mathrm{Cr}-\mathrm{El}, \mathrm{C}$ ).

\section{COFA/I308/Cr-El system}

This system was chosen as a model formulation to study the influence of time and drug loading on formulation turbidity upon aqueous dilution. Formulation turbidity was assessed by measuring the optical density at $600 \mathrm{~nm}$ (Date, Nagarsenker, 2007; Thakkar et al., 2011). On the basis of preliminary self-emulsification and solubility data, the range for each component was selected as follows:

$$
\begin{gathered}
10 \leq \mathrm{COFA} \leq 50 \\
0 \leq \mathrm{I} 308 \leq 60 \\
30 \leq \mathrm{Cr}-\mathrm{E} 1 \leq 70 \\
\text { Total components }=100
\end{gathered}
$$

The base design suggested 17 runs for the fitting of a special cubic model, a check for lack of fit, and an estimate of experimental error in formulation $\mathrm{OD}_{600}$ (Mukherjee, Plakogiannis, 2010).

The design included the assessment of five responses as follows:

R1: $\mathrm{OD}_{600}$ after 5 min of aqueous dilution of $\mathrm{CN}$ free formulation; $\mathrm{R} 2: \mathrm{OD}_{600}$ after $1 \mathrm{~h}$ of aqueous dilution of $\mathrm{CN}$-free formulation; $\mathrm{R} 3: \mathrm{OD}_{600}$ after $5 \mathrm{~min}$ of aqueous dilution of $\mathrm{CN}$-equilibrated formulation; $\mathrm{R} 4: \mathrm{OD}_{600}$ after $1 \mathrm{~h}$ of aqueous dilution of $\mathrm{CN}$-equilibrated formulation; $\mathrm{R} 5: \mathrm{OD}_{600}$ after $2 \mathrm{~h}$ of aqueous dilution of $\mathrm{CN}$-equilibrated formulation.

\section{OL/I308/Cr-El system}

On the basis of preliminary self-emulsification and solubility data, the range of each component was selected as follows:

$$
\begin{gathered}
10 \leq \mathrm{OL} \leq 30 \\
10 \leq \mathrm{I} 308 \leq 40 \\
30 \leq \mathrm{Cr}-\mathrm{El} \leq 70 \\
\text { Total components }=100
\end{gathered}
$$

The base design suggested U_Pseudo coding with 16 runs for the fitting of a quadratic model, a check for lack of fit, and an estimate of experimental error (Mukherjee, Plakogiannis, 2010).

The design included the assessment of three responses as follows:

R1: droplet size after $1 \mathrm{~h}$ of aqueous dilution of drug-free formulation (nm); R2: droplet size after $1 \mathrm{~h}$ of aqueous dilution of drug-equilibrated formulation $(\mathrm{nm})$; R3: equilibrium solubility ( $\mathrm{mg} / \mathrm{g}$ ).

\section{Cross polarizing light microscopy}

Liquid SNEF samples were transferred onto microscope slides and coverslipped a few minutes prior to examination. Samples were then examined using 
crossed polarized light microscopy (Carl Zeiss, Axio lab. A1 (equipped with camera), Jena, Germany) (Mohsin, Long, Pouton, 2009; Mohsin, Pouton, 2012). Samples were examined for the existence of birefringence, a characteristic of liquid crystals, at a magnification of $40 \times$ (Kossena et al., 2004). Liquid crystalline (LC) phases were further identified as hexagonal or lamellar based on the observed birefringence patterns. Within the current study, liquid SNEF samples were examined to investigate the influence of $\mathrm{CN}$ loading on birefringence patterns in anhydrous samples, as well as 30\% and 50\% water dilution samples.

\section{Determination of $\mathrm{CN}$ by using UPLC assay}

$\mathrm{CN}$ was accurately quantified by using a recently reported UPLC reversed-phase method (Abdel-Hamid et al., 2012) with minor modifications. The mobile phase composition was altered to $0.5 \%$ trifluroacetic acid:acentonitrile $(55: 45)$ and the run time was increased to $1.5 \mathrm{~min}$ to allow for higher resolution between the intact drug and degradation product peaks. Separation was achieved using an Acquity ${ }^{\circledR}$ UPLC BEH C18 $(2.1 \times 50$ $\mathrm{mm}, 1.7 \mu \mathrm{m})$ column along with an Acquity guard filter, maintained at $50{ }^{\circ} \mathrm{C}$, and the flow rate was maintained at $0.5 \mathrm{ml} / \mathrm{min}$. The UV detector was set at $251 \mathrm{~nm}$ and the injection volume was $1.0 \mu 1$.

\section{Statistical analysis}

The statistical significance of the results was analyzed using SPSS $22^{\circledR}$ software. One-way analysis of variance (ANOVA) followed by post hoc tests (LSD) were applied to compare solubility results (Atef, Belmonte, 2008; Shahba, Mohsin, Alanazi, 2012a). A value of $p<0.05$ was considered significant.

\section{RESULTS AND DISCUSSION}

\section{Equilibrium solubility studies}

CN solubility was previously screened in diverse formulation compositions (Shahba, Mohsin, Alanazi, 2012a). In the current study, we aimed to maximize CN solubility and to develop a formulation design framework for weakly basic lipophilic drugs. Being a weak base, it was crucial to investigate the influence of formulation acidification on $\mathrm{CN}$ solubility. Formulation acidification was achieved using either an external acidifier (represented by $\mathrm{HCl}$ ) or an internal acidifier (represented by free fatty acid present in the formulation).

\section{Influence of external acidification on CN solubility}

The influence of formulation acidification on $\mathrm{CN}$ solubility was investigated by acidifying SNEF by using $37 \% \mathrm{HCl}$ solution as the external acidifier. $\mathrm{HCl}$ solution was added to the formulation at $1 \%, 2 \%$, and $5 \% \mathrm{w} / \mathrm{w}$. Preliminary data revealed that $2 \% \mathrm{HCl}$ acidification showed the highest $\mathrm{CN}$ solubilization. This finding might be explained by the high formulation water content that led to lower $\mathrm{CN}$ solubilization in case of $5 \%$ acidification.

The study involved investigating the acidification of two formulations: medium chain triglyceride (MCT) based-formulation and long chain fatty acid (LCFA) based-formulation. In case of MCT formulations, 2\% acidification resulted in a $100 \%$ solubility increase relative to the non-acidified counterpart. However, the $2 \%$ acidified LCFA formulation showed a $30 \%$ increase relative to the non-acidified counterpart (Figure 1). The solubility increase upon acidification complies with the fact that $\mathrm{CN}$ is a weak base and its solubility increases with decreasing pH (Gu et al., 2005). Similar results have been obtained with other weakly basic drugs, such as albendazole, which was shown to present increased solubility with increased concentrations of acidified $\mathrm{PEG}_{400}$ in the formulation (Mukherjee, Plakogiannis, 2010). The solubility increase upon formulation

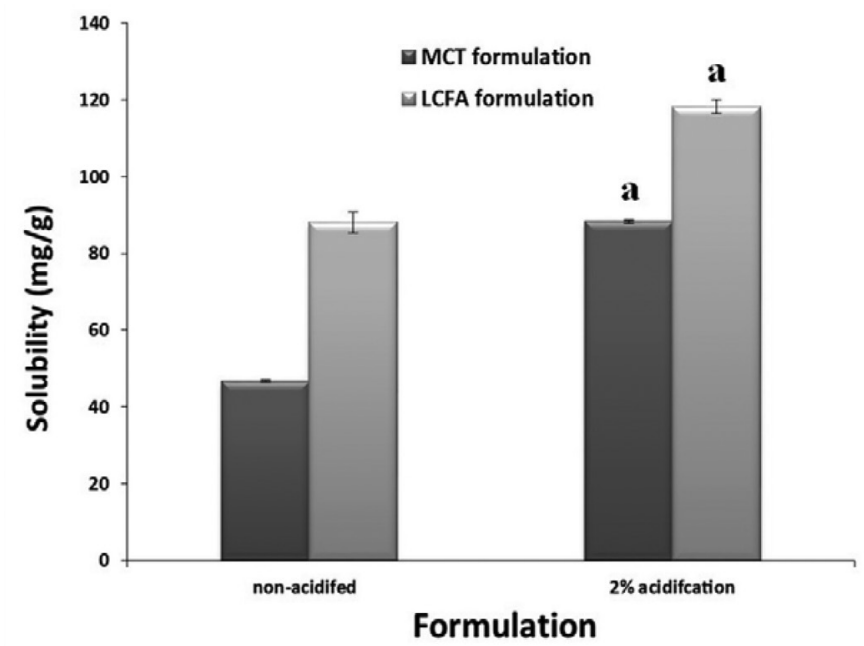

FIGURE 1 - Influence of external formulation acidification on CN solubility. MCT: medium chain triglycerides, LCFA: long chain fatty acid. Non-acidified MCT formulation was represented by M812/I308/T85 (25/25/50); 2\% acidified MCT formulation by M812/1308/T85/ $\mathrm{HCl}(24 / 24 / 50 / 2)$; non-acidified LCFA formulation by OL/1308/Cr-El (25/25/50); $2 \%$ acidified LCFA formulation by OL/1308/Cr-El/HCl (24.5/24.5/49/2). a denotes significant difference $(p<0.05)$ from the corresponding non-acidified formulation. Data are expressed as mean \pm S.D., $\mathrm{n}=3-6$. 
acidification may be due to drug super-saturation or the transient formation of hydrochloride salts.

\section{Influence of internal acidification (free fatty acids versus ester form)}

$\mathrm{CN}$ shows significant solubility increase upon increasing the acidity of aqueous systems (Gu et al., 2005). Interestingly, this phenomenon was also predominant in lipid-based systems (Figures 2 and 3).

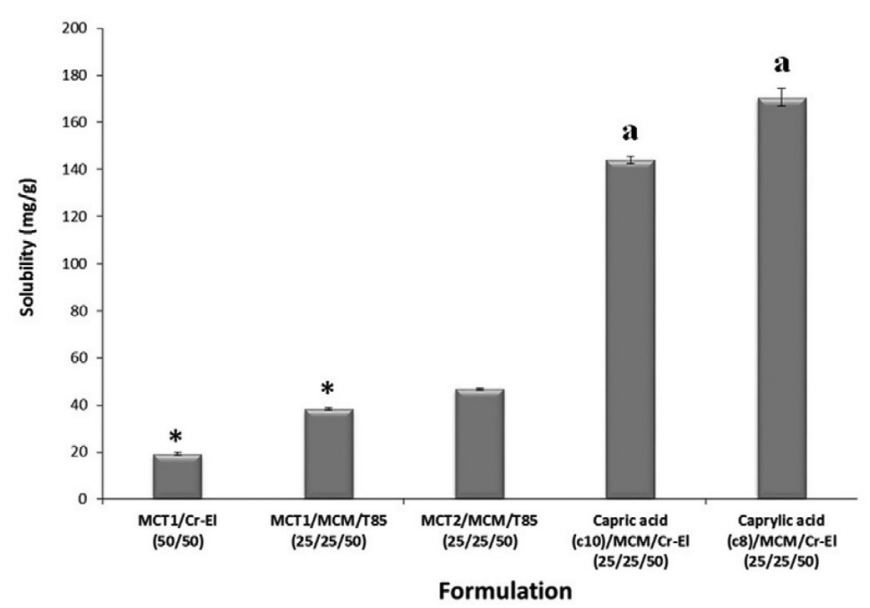

FIGURE 2 - Influence of internal formulation acidification on $\mathrm{CN}$ solubility in capric/caprylic acid-based formulations. MCT1 denotes medium chain capric/caprylic triglycerides (M810), MCT2 denotes medium chain capric/caprylic triglycerides (M812), and MCM denotes medium chain capric/caprylic mono-glycerides (I308). *: Data adapted from Shahba, Mohsin, Alanazi, 2012a; a: significant difference $(\mathrm{p}<0.05)$ from other formulations. Data are expressed as mean \pm S.D., $n=3$.

Capric and caprylic acid (free fatty acids) formulations showed significantly $(\mathrm{p}<0.05)$ higher $\mathrm{CN}$ solubility relative to other capric/caprylic ester formulations (Figure 2). It seems that free fatty acids significantly increase $\mathrm{CN}$ solubility by acting as lipophilic solubilizers, as well as internal acidifiers.

Similarly, a COFA (high \% of free lauric acid)-based formulation showed significantly $(\mathrm{p}<0.05)$ higher $\mathrm{CN}$ solubility relative to other lauric acid monoglycerides (esters) formulations (Figure 3).

\section{Influence of fatty acid chain length}

A more focused study was conducted to evaluate the influence of changing the fatty acid type within the formulation (Figure 4). CN solubility was significantly $(\mathrm{p}<0.05)$ increased upon decreasing fatty acid chain length. This finding may appear inconsistent with the finding of a previous study (Shahba, Mohsin, Alanazi,

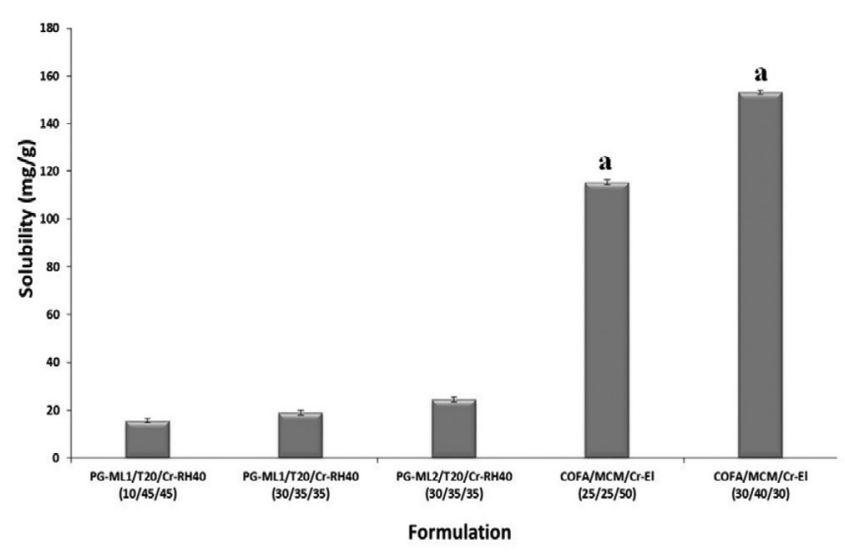

FIGURE 3 - Influence of internal formulation acidification on $\mathrm{CN}$ solubility in lauric acid-based formulations. PG-ML1 denotes propylene glycol monolaurate (Lauroglycol 90), PGML2 denotes propylene glycol monolaurate (Capmul PG-12). T20: Tween 20; Cr-RH40: Cremophor RH40; COFA: coconut oil free fatty acids (high \% of lauric acid); MCM: medium chain capric/caprylic mono-glycerides (I308). a: significant difference $(\mathrm{p}<0.05)$ from other formulations. Data are expressed as mean \pm S.D., $n=3$.

2012a) that showed higher CN solubility in long chain lipid formulations. However, thorough data review revealed that the previously compared formulations were uneven since the previous study (Shahba, Mohsin, Alanazi, 2012a) compared long chain free fatty acid with medium chain ester formulations. For a fair comparison, formulators should consider whether the evaluated fatty acid is in the free or ester form.

The phenomenon found in Figure 4 was correlated with the fact that the acid value of fatty acids increases as the fatty acid chain length decreases. Finally, a direct linear relationship was established between the reported acid value of the fatty acids in the formulation and $\mathrm{CN}$ solubility (Figure 5). CN solubility significantly $(\mathrm{p}<0.05)$ increased as the acid value increased. This point provides a suggested platform for the formulation design of weakly basic lipophilic drugs.

\section{Self-emulsification assessment}

\section{Influence of external acidification}

Medium chain glyceride formulations (acidified by $\mathrm{HCl}$ ) showed satisfactory self-emulsification behavior upon water and acidic dilution at $\mathrm{pH}$ 1.2. However, all formulations (except for the 5\% acidified formulation) presented indispersible flakes upon shifting from $\mathrm{pH} 1.2$ to $\mathrm{pH} 6.8$ (Table I). This may be due to the interaction of the hydrochloride salt present in the formulation with the buffer salts of the alkaline media. 


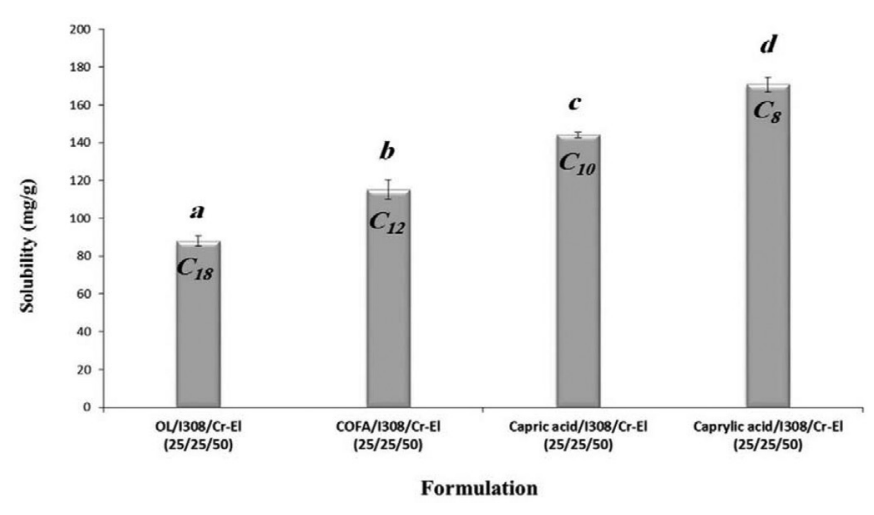

FIGURE 4 - Influence of fatty acid chain length on CN solubility. OL denotes oleic acid (c18) and COFA denotes coconut oil free fatty acids (high \% of lauric acid, C12). Different letters above the bars indicate significant difference $(p<0.05)$ between the solubility values. Data are expressed as mean \pm S.D., $n=3-6$.

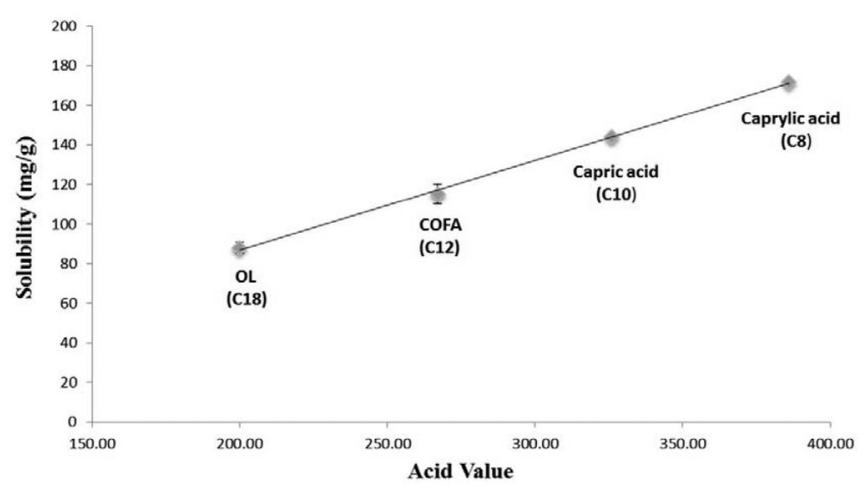

FIGURE 5 - Influence of the acid value of the oil portion on $\mathrm{CN}$ solubility in the whole formulation. The oil portion represented $25 \%$ of the formulation while the remaining excipients were kept constant as 25\% I308 and 50\% Cr-El. OL denotes oleic acid (c18) and COFA denotes coconut oil free fatty acids (high $\%$ of lauric acid, C12). Data are expressed as mean \pm S.D., $n=3-6$.

\section{Influence of internal acidification}

Incorporation of free fatty acids in SNEFs offers dual advantages of serving as lipophilic portions as well as internal acidifiers within the formulation. Different fatty acids were assessed in order to explore their influence on formulation self-emulsifying efficiency.

Although some formulations containing COFA showed efficient self-emulsification upon water and acidic dilution, they presented indispersible flakes upon shifting to $\mathrm{pH} 6.8$ (Table II). A follow-up study was conducted to assess whether buffer salts interact with formulation components and produce these flakes. To distinguish the influence of the buffer salts, both formulation components and solution $\mathrm{pH}$ were maintained nearly equal while various buffer salts were investigated. COFA/I308/HCO$60(25 / 25 / 50)$ was selected as a control formulation and various buffer salts (with solution $\mathrm{pH}=6.8 \pm 1$ ) were assessed (Table III). The model formulation presented poor homogeneity/dispersibility with all the investigated buffer salts. These results suggest that the poor selfemulsification of the COFA formulation (at $\mathrm{pH}$ 6.8) might be related to the fatty acid itself rather than any interaction with the buffer salts.

Most capric acid (c10) and caprylic acid (c8) formulations showed excellent self-emulsification behavior upon acidic dilution (Table IV). However, they presented poor homogeneity/dispersibility upon shifting to $\mathrm{pH}$ 6.8. On the other hand, OL formulations exhibited superior performance compared with other fatty acids (Table V). Most of the tested formulations showed excellent self-emulsification in water, at $\mathrm{pH} 1.2$, and even at $\mathrm{pH}$ 6.8. This observation is in agreement with recent studies (Larsen et al., 2012; Patel, Sarma, Vavia, 2013) where OL self-emulsifying formulations have exhibited excellent self-emulsification in all tested media. This promising OL characteristic might be explained by the low acid value of OL compared with other fatty acids (Figure 5) leading to a decreased precipitation tendency at $\mathrm{pH}$ 6.8. Another possible reason may be that OL is thought to behave as a co-surfactant at neutral $\mathrm{pH}$ (Larsen et al., 2012).

The aforementioned discussion highlights the importance of conducting the self-emulsification assessment in three different media (distilled water, $\mathrm{pH}$ 1.2 , and $\mathrm{pH} 6.8$ ), especially for weakly basic drugs. The usual practice of conducting the self-emulsification assessment in water only could lead to inaccurate excipient selection, resulting in wasted time and unsuccessful formulation optimization.

\section{Experimentally designed phase diagrams}

For each phase diagram, dots represented the investigated points in the design. Dots marked with a " 2 " or a " 3 " indicate points that were duplicated or triplicated, respectively. The analysis of response variables were carried out by using Design Expert ${ }^{\circledR}$ software. Data transformation was performed if necessary. Model fitting was carried out to select a model with insignificant lackof-fit, high adjusted and predicted R-squared values, small standard deviation, small predicted residual sum of squares (press), and no aliasing (Mukherjee, Plakogiannis, 2010).

\section{COFA/I308/Cr-El system}

The D-optimal mixture design was applied to examine the influence of varying formulation components 
TABLE I - Influence of $\mathrm{HCl}$ acidification on self-emulsification efficiency in medium chain glyceride formulations

\begin{tabular}{|c|c|c|c|c|c|}
\hline $\begin{array}{l}\text { Formulation } \\
(\% \mathrm{~W} / \mathrm{W})\end{array}$ & $\begin{array}{l}\text { Excipient } \\
\text { miscibility }\end{array}$ & $\begin{array}{l}\text { Aqueous } \\
\text { media }\end{array}$ & $\begin{array}{l}\text { Homogeneity/ } \\
\text { dispersibility }\end{array}$ & Spontaneity & $\begin{array}{c}\text { Overall } \\
\text { performance }\end{array}$ \\
\hline \multirow{3}{*}{$\begin{array}{l}\text { M812/I308/T85 } \\
(25 / 25 / 50)\end{array}$} & \multirow{3}{*}{ miscible } & D.W & good & $<1 \min$ & $\sqrt{ }$ \\
\hline & & pH 1.2 & good & $<1 \min$ & $\sqrt{ }$ \\
\hline & & shift to $\mathrm{pH} 6.8$ & poor & - & $\times$ \\
\hline \multirow{3}{*}{$\begin{array}{l}\mathrm{M} 812 / \mathrm{I} 308 / \mathrm{T} 85 / \mathrm{HCl} \\
(24.5 / 24.5 / 50 / 1)\end{array}$} & \multirow{3}{*}{ miscible } & D.W & good & $<1 \min$ & $\sqrt{ }$ \\
\hline & & $\mathrm{pH} 1.2$ & good & $<1 \min$ & $\sqrt{ }$ \\
\hline & & shift to $\mathrm{pH} 6.8$ & poor & - & $\times$ \\
\hline \multirow{3}{*}{$\begin{array}{l}\mathrm{M} 812 / \mathrm{I} 308 / \mathrm{T} 85 / \mathrm{HCl} \\
(24 / 24 / 50 / 2)\end{array}$} & \multirow{3}{*}{ miscible } & D.W & good & $<1 \min$ & $\sqrt{ }$ \\
\hline & & $\mathrm{pH} 1.2$ & good & $<1 \min$ & $\sqrt{ }$ \\
\hline & & shift to $\mathrm{pH} 6.8$ & poor & - & $\times$ \\
\hline \multirow{3}{*}{$\begin{array}{l}\mathrm{M} 812 / \mathrm{I} 308 / \mathrm{T} 85 / \mathrm{HCl} \\
(22.5 / 22.5 / 50 / 5)\end{array}$} & \multirow{3}{*}{ miscible } & D.W & moderate & $<1 \min$ & $\sqrt{ }$ \\
\hline & & pH 1.2 & good & $<1 \min$ & $\sqrt{ }$ \\
\hline & & shift to $\mathrm{pH} 6.8$ & good & - & $\sqrt{ }$ \\
\hline
\end{tabular}

$(\sqrt{ })$ : good self-emulsifying efficiency; (×): poor self-emulsifying efficiency; M812: miglyol 812; I308: Imwitor 308; T85: tween 85.

TABLE II - Influence of internal acidification by COFA on formulation self-emulsifying efficiency

\begin{tabular}{|c|c|c|c|c|c|}
\hline Formulation $(\% \mathrm{~W} / \mathrm{W})$ & $\begin{array}{c}\text { Excipient } \\
\text { miscibility }\end{array}$ & $\begin{array}{c}\text { Aqueous } \\
\text { media }\end{array}$ & $\begin{array}{l}\text { Homogeneity/ } \\
\text { dispersibility }\end{array}$ & $\begin{array}{c}\text { Spontaneity } \\
\text { (min) }\end{array}$ & $\begin{array}{c}\text { Overall } \\
\text { performance }\end{array}$ \\
\hline \multirow{2}{*}{$\begin{array}{l}\text { COFA/I308/Cr-El } \\
(25 / 25 / 50)\end{array}$} & \multirow{2}{*}{ miscible } & pH 1.2 & poor & $<1$ & $x$ \\
\hline & & shift to $\mathrm{pH} 6.8$ & poor & - & $\times$ \\
\hline \multirow{2}{*}{$\begin{array}{l}\text { COFA/1308/Cr-El } \\
(10 / 20 / 70)\end{array}$} & \multirow{2}{*}{ miscible } & $\mathrm{pH} 1.2$ & good & $<1$ & $\sqrt{ }$ \\
\hline & & shift to $\mathrm{pH} 6.8$ & poor & - & $\times$ \\
\hline \multirow{2}{*}{$\begin{array}{l}\text { COFA/S218/Cr-El } \\
(25 / 25 / 50)\end{array}$} & \multirow{2}{*}{ miscible } & $\mathrm{pH} 1.2$ & good & $<1$ & $\sqrt{ }$ \\
\hline & & shift to $\mathrm{pH} 6.8$ & poor & - & $\times$ \\
\hline \multirow{2}{*}{$\begin{array}{l}\text { COFA/I308/T80 } \\
(25 / 25 / 50)\end{array}$} & \multirow{2}{*}{ miscible } & $\mathrm{pH} 1.2$ & good & $<1$ & $\sqrt{ }$ \\
\hline & & shift to $\mathrm{pH} 6.8$ & poor & - & $\times$ \\
\hline \multirow{2}{*}{$\begin{array}{l}\text { COFA/I308/T20 } \\
(25 / 25 / 50)\end{array}$} & \multirow{2}{*}{ miscible } & $\mathrm{pH} 1.2$ & good & $<1$ & $\sqrt{ }$ \\
\hline & & shift to $\mathrm{pH} 6.8$ & poor & - & $x$ \\
\hline \multirow{2}{*}{$\begin{array}{l}\text { COFA/I308/PG/Cr-El } \\
(25 / 15 / 10 / 50) \\
\end{array}$} & \multirow{2}{*}{ miscible } & $\mathrm{pH} 1.2$ & good & $<1$ & $\sqrt{ }$ \\
\hline & & shift to $\mathrm{pH} 6.8$ & poor & - & $\times$ \\
\hline \multirow{2}{*}{$\begin{array}{l}\text { COFA/I308/M812/Cr-El } \\
(25 / 12.5 / 12.5 / 50)\end{array}$} & \multirow{2}{*}{ miscible } & $\mathrm{pH} 1.2$ & good & $<1$ & $\sqrt{ }$ \\
\hline & & shift to $\mathrm{pH} 6.8$ & poor & - & $x$ \\
\hline \multirow{2}{*}{$\begin{array}{l}\text { COFA/T85/Cr-El } \\
(33.3 / 33.3 / 33.3)\end{array}$} & \multirow{2}{*}{ miscible } & $\mathrm{pH} 1.2$ & good & $<1$ & $\sqrt{ }$ \\
\hline & & shift to $\mathrm{pH} 6.8$ & poor & - & $x$ \\
\hline \multirow{2}{*}{$\begin{array}{l}\text { COFA/I308/HCO-60 } \\
(25 / 25 / 50)\end{array}$} & \multirow{2}{*}{ miscible } & $\mathrm{pH} 1.2$ & good & $<1$ & $\sqrt{ }$ \\
\hline & & shift to $\mathrm{pH} 6.8$ & poor & - & $x$ \\
\hline
\end{tabular}

$(\sqrt{ })$ : good self-emulsifying efficiency; $(\times)$ : poor self-emulsifying efficiency; COFA: coconut oil fatty acids; I308: Imwitor 308; S218: sefsol 218; Cr-El: cremophor El; M812: miglyol 812; T20: Tween 20; PG: propylene glycol; T80: Tween 80.

on formulation $\mathrm{OD}_{600}$ after aqueous dilution at five different stages (Figures 6 and 7). The first and second responses were conducted using $\mathrm{CN}$-free formulation (Figure 6).
There was no substantial difference between $\mathrm{OD}_{600}$ at 5 min and $1 \mathrm{~h}$ after aqueous dilution of $\mathrm{CN}$-free formulations (Figure $6[\mathrm{~A}, \mathrm{~B}]$ ). Both phase diagrams showed small 
TABLE III - Influence of varying buffer solutions on formulation self-emulsifying efficiency

\begin{tabular}{|c|c|c|c|c|c|}
\hline Formulation $(\% \mathrm{~W} / \mathrm{W})$ & Buffer solution & pH & $\begin{array}{l}\text { Homogeneity/ } \\
\text { dispersibility }\end{array}$ & $\begin{array}{l}\text { Spontaneity } \\
\quad(\text { min) }\end{array}$ & $\begin{array}{c}\text { Overall } \\
\text { performance }\end{array}$ \\
\hline $\begin{array}{l}\text { COFA/I308/HCO-60 } \\
(25 / 25 / 50)\end{array}$ & $\begin{array}{c}\mathrm{K}_{2} \mathrm{HPO}_{4}, \mathrm{KH}_{2} \mathrm{PO}_{4} \\
\mathrm{NaOH}\end{array}$ & 7.5 & poor & $<1$ & $x$ \\
\hline $\begin{array}{l}\text { COFA/I308/HCO-60 } \\
(25 / 25 / 50)\end{array}$ & $\mathrm{Na}_{2} \mathrm{HPO}_{4}, \mathrm{KH}_{2} \mathrm{PO}_{4}$ & 6.8 & poor & $<1$ & $\times$ \\
\hline $\begin{array}{l}\text { COFA/I308/HCO-60 } \\
(25 / 25 / 50)\end{array}$ & $\begin{array}{l}\text { Na-acetate, } \\
0.1 \mathrm{~N} \mathrm{HCl}\end{array}$ & 5.9 & poor & $<1$ & $x$ \\
\hline $\begin{array}{l}\text { COFA/I308/HCO-60 } \\
(25 / 25 / 50)\end{array}$ & $\begin{array}{c}\text { tri-Na citrate, } \\
0.1 \mathrm{~N} \mathrm{HCl}\end{array}$ & 6.65 & poor & $<1$ & $x$ \\
\hline $\begin{array}{l}\text { COFA/I308/HCO-60 } \\
(25 / 25 / 50)\end{array}$ & $\begin{array}{l}\mathrm{K}_{2} \mathrm{HPO}_{4}, \\
0.1 \mathrm{~N} \mathrm{HCl}\end{array}$ & 6.75 & poor & $<1$ & $x$ \\
\hline $\begin{array}{l}\text { COFA/I308/HCO-60 } \\
(25 / 25 / 50)\end{array}$ & $\begin{array}{l}\text { Na-acetate, } \\
\mathrm{NaOH}\end{array}$ & 6.7 & poor & $<1$ & $x$ \\
\hline
\end{tabular}

$(\sqrt{ })$ : good self-emulsifying efficiency; $(\times)$ : poor self-emulsifying efficiency; COFA: coconut oil fatty acids; I308: Imwitor 308.

TABLE IV - Influence of internal acidification by capric (c10) and caprylic (c8) acid on formulation self-emulsifying efficiency

\begin{tabular}{|c|c|c|c|c|c|}
\hline Formulation $(\% \mathrm{~W} / \mathrm{W})$ & $\begin{array}{c}\text { Excipient } \\
\text { miscibility }\end{array}$ & $\begin{array}{l}\text { Aqueous } \\
\text { media }\end{array}$ & $\begin{array}{l}\text { Homogeneity/ } \\
\text { dispersibility }\end{array}$ & $\begin{array}{c}\text { Spontaneity } \\
(\min )\end{array}$ & $\begin{array}{c}\text { Overall } \\
\text { performance }\end{array}$ \\
\hline \multirow{2}{*}{$\begin{array}{l}\text { Capric acid (c10)/I308/Cr-El } \\
(25 / 25 / 50)\end{array}$} & \multirow{2}{*}{ miscible } & $\mathrm{pH} 1.2$ & good & $<1$ & $\sqrt{ }$ \\
\hline & & shift to $\mathrm{pH} 6.8$ & poor & - & $x$ \\
\hline \multirow{2}{*}{$\begin{array}{l}\text { Capric acid (c10)/1308/T20 } \\
(25 / 25 / 50)\end{array}$} & \multirow{2}{*}{ miscible } & $\mathrm{pH} 1.2$ & good & $<1$ & $\sqrt{ }$ \\
\hline & & shift to $\mathrm{pH} 6.8$ & poor & - & $x$ \\
\hline \multirow{2}{*}{$\begin{array}{l}\text { Capric acid (c10)/I308/Cr-RH40 } \\
(25 / 25 / 50)\end{array}$} & \multirow{2}{*}{ miscible } & $\mathrm{pH} 1.2$ & good & $<1$ & $\sqrt{ }$ \\
\hline & & shift to $\mathrm{pH} 6.8$ & poor & - & $x$ \\
\hline \multirow{2}{*}{$\begin{array}{l}\text { Capric acid (c10)/1308/T85 } \\
(25 / 25 / 50)\end{array}$} & \multirow{2}{*}{ miscible } & $\mathrm{pH} 1.2$ & good & $1-5$ & $\sqrt{ }$ \\
\hline & & shift to $\mathrm{pH} 6.8$ & poor & - & $x$ \\
\hline \multirow{2}{*}{$\begin{array}{l}\text { Capric acid (c10)/I308/HCO-30 } \\
(25 / 25 / 50)\end{array}$} & \multirow{2}{*}{ miscible } & $\mathrm{pH} 1.2$ & good & $<1$ & $\sqrt{ }$ \\
\hline & & shift to $\mathrm{pH} 6.8$ & poor & - & $x$ \\
\hline \multirow{2}{*}{$\begin{array}{l}\text { Capric acid (c10)/I988/Cr-El } \\
(25 / 25 / 50)\end{array}$} & \multirow{2}{*}{ miscible } & $\mathrm{pH} 1.2$ & good & $<1$ & $\sqrt{ }$ \\
\hline & & shift to $\mathrm{pH} 6.8$ & poor & - & $x$ \\
\hline \multirow{2}{*}{$\begin{array}{l}\text { Caprylic acid (c8)/I308/Cr-El } \\
(25 / 25 / 50)\end{array}$} & \multirow{2}{*}{ miscible } & $\mathrm{pH} 1.2$ & good & $<1$ & $\sqrt{ }$ \\
\hline & & shift to $\mathrm{pH} 6.8$ & poor & - & $x$ \\
\hline
\end{tabular}

$(\sqrt{ })$ : good self-emulsifying efficiency; $(\times)$ : poor self-emulsifying efficiency; I308: Imwitor 308; 1988: Imwitor 988; Cr-El: cremophor El; Cr-Rh40: cremophor RH40; T20: Tween 20; T85: Tween 85.

bluish and large turbid and milky areas. On the other hand, CN-equilibrated formulations showed significant decrease in $\mathrm{OD}_{600}$ compared to their $\mathrm{CN}$-free counterparts (Figure 6 [A, B], Figure 7 [A, B]). At $5 \mathrm{~min}$, the phase diagram showed large transparent and bluish areas with no existence of turbid or milky areas (Figure 7A). At subsequent ( $1 \mathrm{~h}$ and $2 \mathrm{~h}$ ) samples, $\mathrm{OD}_{600}$ showed a gradual shift upwards and a turbid area started to appear at the expense of the transparent area (Figure $7[\mathrm{~B}, \mathrm{C}]$ ). It is worth noticing that all formulations showed sharply lower $\mathrm{OD}_{600}$ values after equilibration with $\mathrm{CN}$. This is an unusual phenomenon because $\mathrm{CN}$ is a PWSD and its incorporation was expected to increase formulation turbidity upon aqueous dilution. For further investigation 
TABLE V - Influence of internal acidification by OL on formulation self-emulsifying efficiency

\begin{tabular}{|c|c|c|c|c|c|}
\hline $\begin{array}{l}\text { Formulation } \\
(\% \mathrm{~W} / \mathrm{W})\end{array}$ & Aqueous media & $\begin{array}{r}\text { Excipient } \\
\text { miscibility }\end{array}$ & $\begin{array}{l}\text { Homogeneity/ } \\
\text { dispersibility }\end{array}$ & $\begin{array}{c}\text { Spontaneity } \\
\text { (min) }\end{array}$ & $\begin{array}{c}\begin{array}{c}\text { Overall } \\
\text { performance }\end{array} \\
\end{array}$ \\
\hline \multirow{2}{*}{$\begin{array}{l}\text { OL/I308/Cr-El } \\
(25 / 25 / 50)\end{array}$} & $\mathrm{pH} 1.2$ & \multirow{2}{*}{ miscible } & good & $<1$ & $\sqrt{ }$ \\
\hline & shift to $\mathrm{pH} 6.8$ & & good & - & $\sqrt{ }$ \\
\hline \multirow{2}{*}{$\begin{array}{l}\mathrm{OL} / \mathrm{I} 308 / \mathrm{Cr}-\mathrm{El} \\
(30 / 30 / 40)\end{array}$} & $\mathrm{pH} 1.2$ & \multirow{2}{*}{ miscible } & good & $<1$ & $\sqrt{ }$ \\
\hline & shift to $\mathrm{pH} 6.8$ & & good & - & $\sqrt{ }$ \\
\hline \multirow{2}{*}{$\begin{array}{l}\text { OL/I308/Cr-El } \\
(30 / 40 / 30)\end{array}$} & $\mathrm{pH} 1.2$ & \multirow{2}{*}{ miscible } & poor & $<1$ & $\bar{x}$ \\
\hline & shift to $\mathrm{pH} 6.8$ & & poor & - & $\times$ \\
\hline \multirow{2}{*}{$\begin{array}{l}\text { OL/I308/HCO-60 } \\
(30 / 40 / 30)\end{array}$} & $\mathrm{pH} 1.2$ & \multirow{2}{*}{ miscible } & good & $<1$ & $\sqrt{ }$ \\
\hline & shift to $\mathrm{pH} 6.8$ & & good & - & $\sqrt{ }$ \\
\hline \multirow{2}{*}{$\begin{array}{l}\text { OL/I308/HCO-60 } \\
(25 / 25 / 50)\end{array}$} & $\mathrm{pH} 1.2$ & \multirow{2}{*}{ immiscible } & good & $<1$ & $x$ \\
\hline & shift to $\mathrm{pH} 6.8$ & & good & - & $x$ \\
\hline
\end{tabular}

$(\sqrt{ })$ : good self-emulsifying efficiency; $(\times)$ : poor self-emulsifying efficiency; OL: oleic acid, I308; Imwitor 308, Cr-El; cremophor El
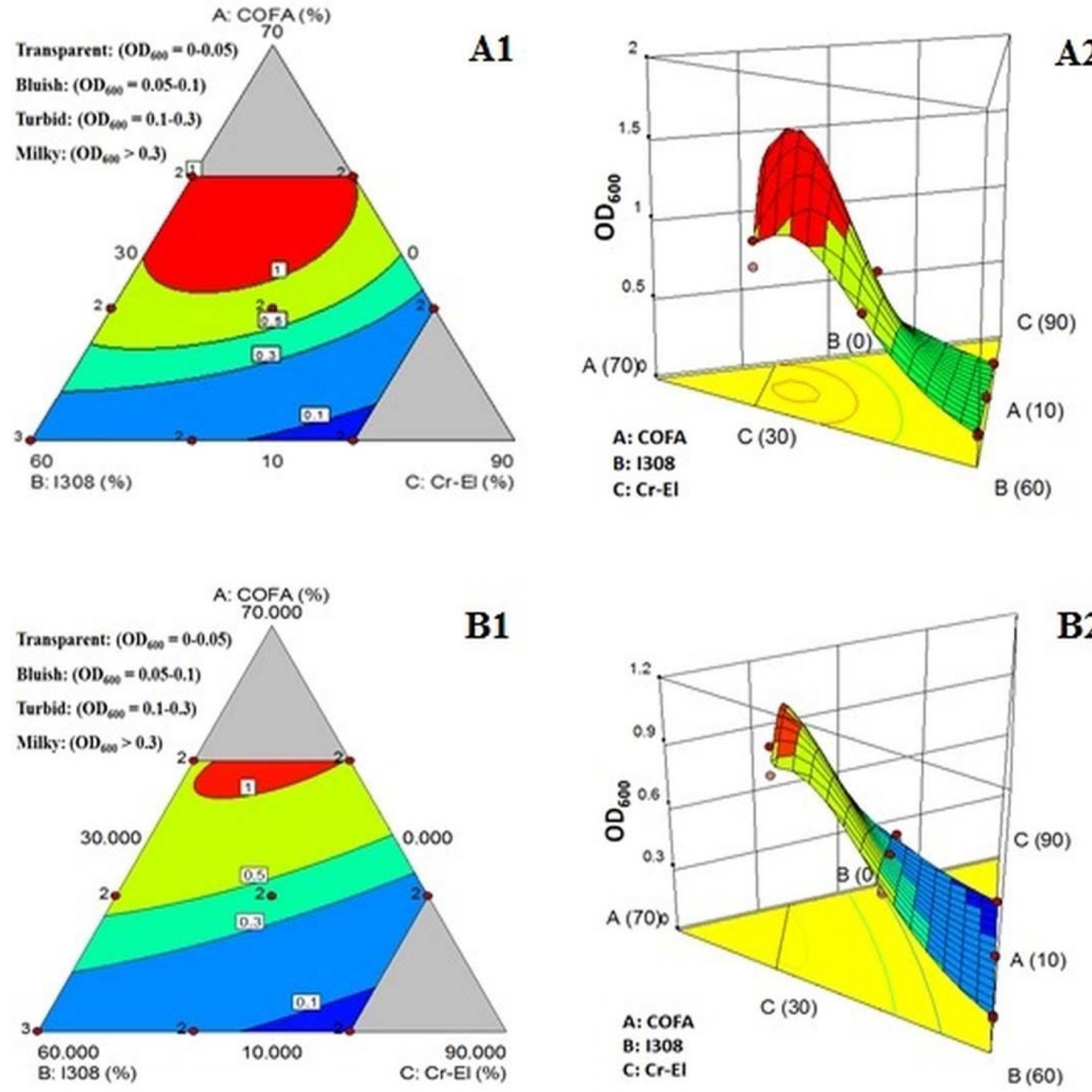

FIGURE 6 - Mixture design for the COFA/I308/Cr-El system showing: $\left(\mathrm{A}_{1}\right)$ phase diagram; $\left(\mathrm{A}_{2}\right): 3 \mathrm{D}$ plot of $\mathrm{OD}_{600}$ after 5 min of aqueous dilution of $\mathrm{CN}$-free formulation; $\left(\mathrm{B}_{1}\right)$ phase diagram; $\left(\mathrm{B}_{2}\right)$ : $3 \mathrm{D}$ plot of $\mathrm{OD}_{600}$ after $1 \mathrm{~h}$ of aqueous dilution of $\mathrm{CN}$-free formulation. COFA denotes coconut oil fatty acids, I308: Imwitor 308, and Cr-El: cremophor El. 

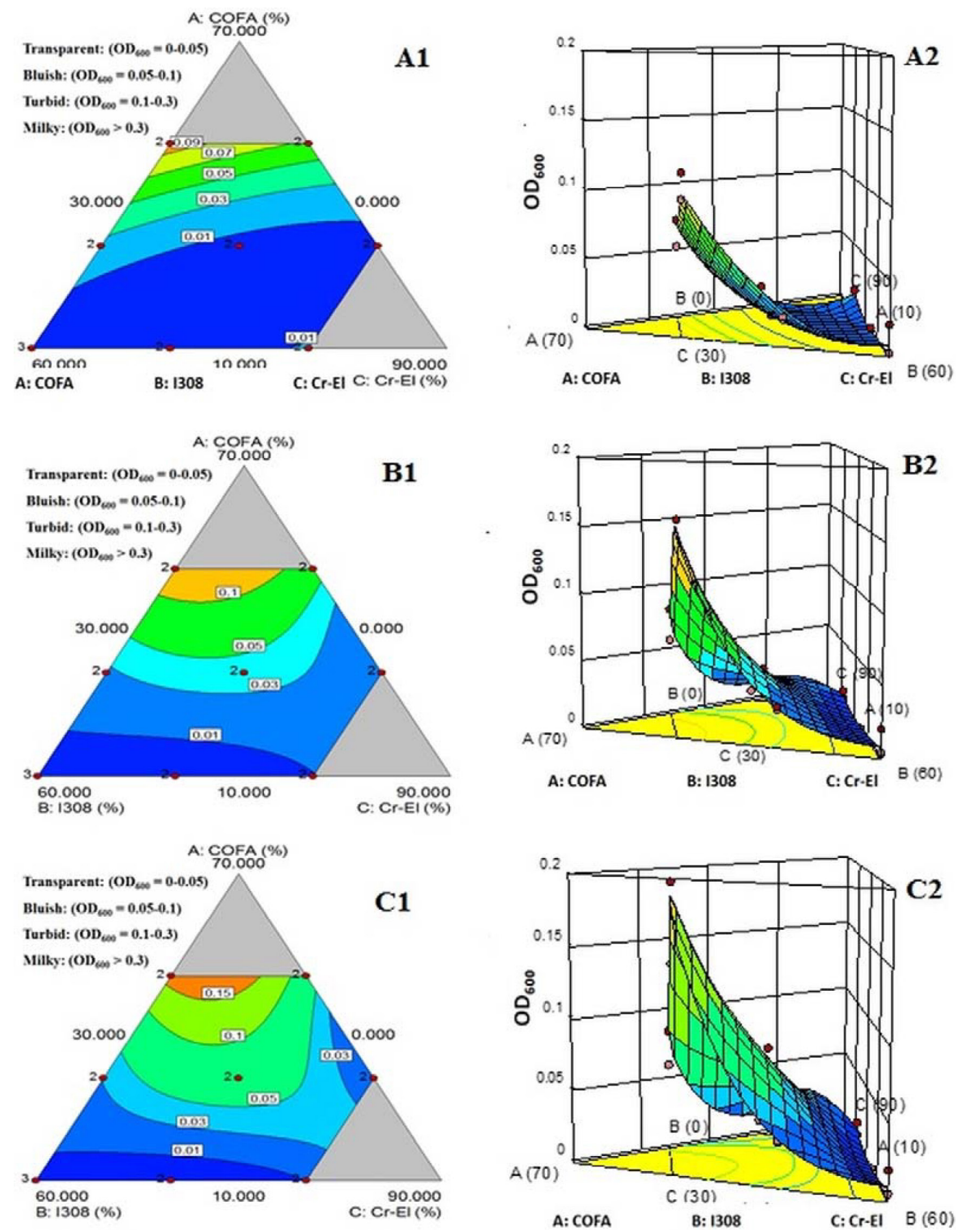

FIGURE 7 - Mixture design for COFA/I308/Cr-El system showing: $\left(\mathrm{A}_{1}\right)$ phase diagram; $\left(\mathrm{A}_{2}\right)$ 3D plot of $\mathrm{OD}_{600}$ after 5 min of aqueous dilution of $\mathrm{CN}$-equilibrated formulation; $\left(\mathrm{B}_{1}\right)$ phase diagram; $\left(\mathrm{B}_{2}\right) 3 \mathrm{D}$ plot of $\mathrm{OD}_{600}$ after $1 \mathrm{~h}$ of aqueous dilution of $\mathrm{CN}$ equilibrated formulation; $\left(\mathrm{C}_{1}\right)$ phase diagram; $\left(\mathrm{C}_{2}\right) 3 \mathrm{D}$ plot of $\mathrm{OD}_{600}$ after $2 \mathrm{~h}$ of aqueous dilution of $\mathrm{CN}$-equilibrated formulation. COFA denotes coconut oil fatty acids, I308: Imwitor 308, and Cr-El: cremophor El.

of this phenomenon, another system was investigated using OL, rather than COFA, as the oil component.

\section{OL/I308/Cr-El system}

D-optimal mixture design was applied to examine the influence of varying formulation components on droplet size and equilibrium solubility. The droplet size of the diluted $\mathrm{CN}$-free formulations showed high variability, ranging from less than $100 \mathrm{~nm}$ up to $\approx 1250 \mathrm{~nm}$ (Figure $8 \mathrm{~A}$ ). Formulations with droplet size above $100 \mathrm{~nm}$ are expected to show a turbid or milky appearance (Shahba, Mohsin, Alanazi, 
2012b). However, formulation phase behavior completely changed upon $\mathrm{CN}$ incorporation (Figure 8B). Diluted $\mathrm{CN}$-equilibrated formulations showed less variability and significantly smaller droplet sizes, with a maximum of 87 $\mathrm{nm}$. This observation closely matches the results obtained in the previous COFA/I308/Cr-El phase diagram, where the incorporation of $\mathrm{CN}$ led to smaller droplet sizes, decreased turbidity, and increased SNEF efficiency. Many researchers have examined the influence of PWSD incorporation into SNEFs on droplet size. Some articles showed droplet size increases upon drug incorporation (Kommuru et al., 2001; Kang et al., 2004), while a few articles showed no droplet size difference upon drug incorporation (Nielsen et al., 2007). However, one recent publication showed significant droplet size decrease upon drug incorporation (Patel, Sarma, Vavia, 2013). This last publication may be in agreement with the current work because it has also investigated a very similar formulation composition (OL/ medium chain monoglycerides/Cr-El) with a weakly basic drug (lumefantrine). According to that recent publication (Patel, Sarma, Vavia, 2013), this phenomenon might be due to the interaction between the drug amine group and the OL carboxylic group, which leads to the formation of an ion-pairing complex. The formed complex presented more efficient self-emulsification and lower droplet sizes than the drug-free formulation. The observed phenomenon could be extrapolated for other weakly basic lipophilic drugs.

The third response involved the equilibrium $\mathrm{CN}$ solubility in anhydrous SNEFs (Figure 8C). Maximum CN solubility was achieved using higher OL and lower $\mathrm{Cr}-\mathrm{El}$ proportions. This result matches the solubility data, which showed a significant $(p<0.05)$ rise in $\mathrm{CN}$ solubility upon increasing the free fatty acid proportion in the formulation (Figure 3).

\section{Experimental model validation}

To achieve the optimum CN-SNEF, it was desirable to select the formulation presenting lower droplet size and higher CN solubility. The formulation [OL/I308/Cr-El $(25 / 25 / 50)]$ was selected as a confirmation point to validate the predictions of the experimental model. The design was utilized to predict the three design responses for this formulation. Experiments were then conducted to obtain the actual response values. All the actual mean values were close to the predicted mean, and fall between the $95 \%$ lower and higher prediction intervals (Table VI). These results confirm the model accuracy in predicting different design responses. The selected formulation showed ultrafine (43 nm) droplet size (in case of CN loading), high ( 88 $\mathrm{mg} / \mathrm{g}$ ) CN solubility, and therefore has great potential to present an efficient CN-SNEF. These results match the recently reported data regarding CN-SNEFs (Shahba, Mohsin, Alanazi, 2012a).

\section{Cross polarizing light microscopy}

The optimal liquid SNEF (OL/I308/Cr-El [25/25/50)] was examined to investigate the influence of $\mathrm{CN}$ loading on the birefringence pattern in anhydrous samples, as well as $30 \%$ and $50 \%$ water dilutions. Anhydrous liquid SNEF showed a transparent isotropic oily phase in both $\mathrm{CN}$-free and $\mathrm{CN}$-equilibrated samples. After hydration, $\mathrm{CN}$-free liquid SNEF showed a two-phase emulsion mixture (without LC) at both $30 \%$ and $50 \%$ water ratios (Figure 9A, B). However, hydrated samples of CN-loaded SNEF became more transparent and presented a birefringent LC phase at $50 \%$ water ratio (Figure 9C, D). On the basis of the observed pattern, this sample was identified as lamellar LC phase (Mohsin, Long, Pouton, 2009; Mohsin, Pouton, 2012). The presence of a lamellar LC phase could lead to the enhancement of the formulation self-emulsification efficiency. A very recent article (Lee et al., 2016) showed pronounced enhancement of bioavailability upon using lamellar LC nanoparticles. It is worth noticing that the LC phase was only observed in the $\mathrm{CN}$-loaded formulation. This is in close correlation with the phenomenon observed in experimentally designed phase diagrams, which showed enhanced SNEF efficiency upon $\mathrm{CN}$ incorporation into the formulation.

\section{CONCLUSION}

Pre-competitive research should be promoted to build-up advanced formulation design frameworks for different PSWD categories. In the current study, we investigated the weakly basic lipophilic drug category by using $\mathrm{CN}$ as a model. The formulation acidity and the $\mathrm{pH}$ of the dispersion media were found to exert strong influences on drug solubility and formulation efficiency, respectively. Formulation acidification produced significant drug solubility increase. It was critical to conduct the self-emulsification assessment in media with different $\mathrm{pH}$ rather than water alone. This step is of particular importance for weakly basic drugs. OL was found to be a vital component in the development of SNEFs for weakly basic lipophilic drugs. It offers several advantages, serving as a lipophilic solubilizer, an internal acidifier, along with maintaining excellent selfnanoemulsification efficiency. As shown in the current study, experimentally designed phase diagrams could be easily utilized for fast, accurate, and reliable optimization 

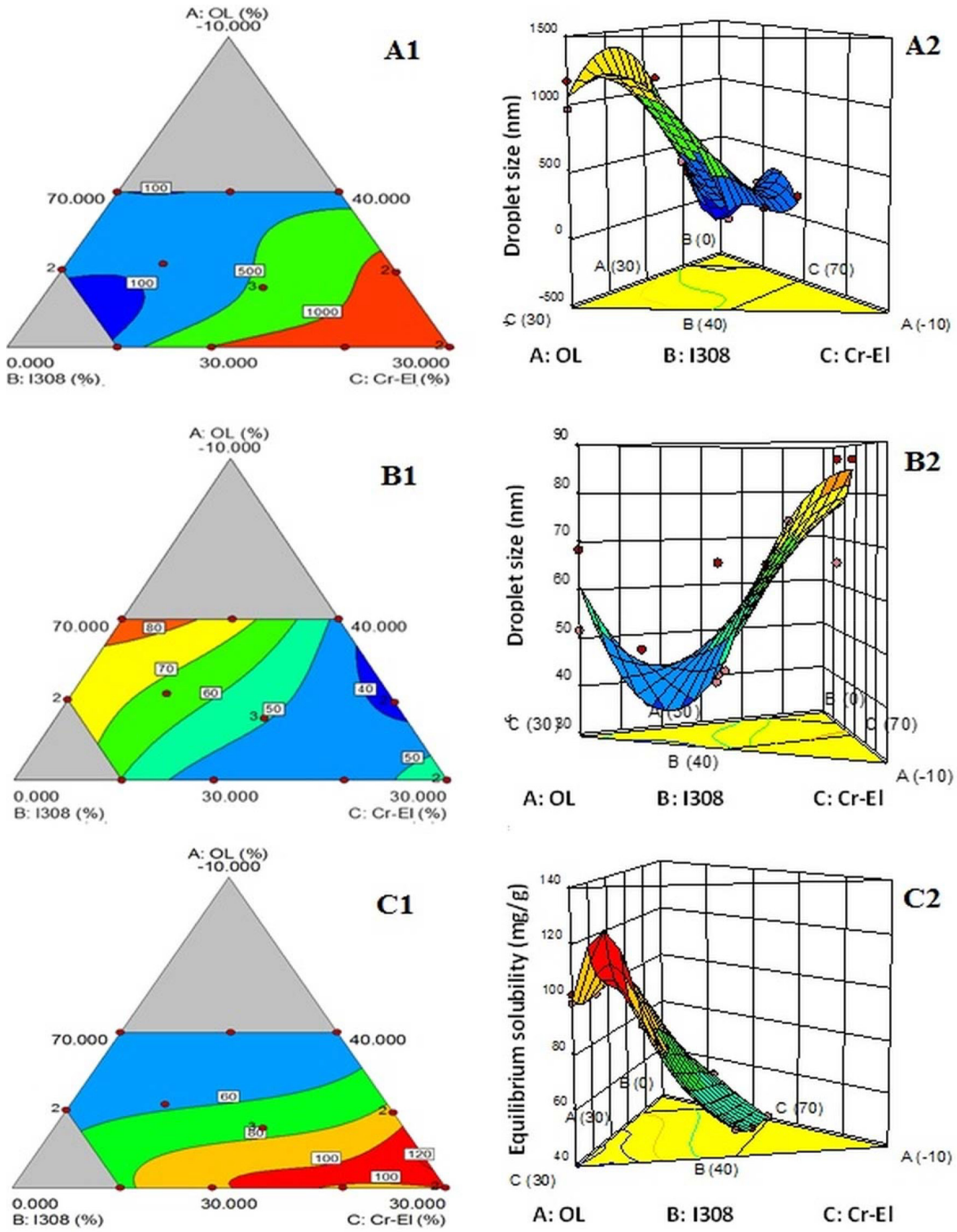

FIGURE 8 - Mixture design for OL/I308/Cr-El system showing: $\left(\mathrm{A}_{1}\right)$ phase diagram; $\left(\mathrm{A}_{2}\right) 3 \mathrm{D}$ plot of droplet size of diluted $\mathrm{CN}$-free formulation $(\mathrm{nm})$; $\left(\mathrm{B}_{1}\right)$ phase diagram; $\left(\mathrm{B}_{2}\right) 3 \mathrm{D}$ plot of droplet size of diluted $\mathrm{CN}$-equilibrated formulation $(\mathrm{nm})$; $\left(\mathrm{C}_{1}\right)$ phase diagram; $\left(\mathrm{C}_{2}\right)$ 3D plot of formulation equilibrium solubility (mg/g). OL denotes oleic acid, I308: Imwitor 308, and Cr-El: cremophor El.

of SNEFs. Future work may involve in vitro dissolution and lipolysis studies in formulation optimization by experimental design. The adopted optimization approach explored critical characterization issues, the role of formulation acidification, SNEF optimization by experimental design, and can be generalized for the whole category of weakly basic lipophilic drugs.

\section{ACKNOWLEDGEMENTS}

This work was funded by the National Plan for Science, Technology, and Innovation (MAARIFAH), King 
TABLE VI - Validation of the experimental design model using the formulation [OL/I308/Cr-EL (25/25/50)]

\begin{tabular}{|c|c|c|c|c|c|c|}
\hline Response & S.D. & n & $\begin{array}{c}\text { Predicted } \\
\text { mean }\end{array}$ & $\begin{array}{c}\text { Actual data } \\
\text { mean }\end{array}$ & 95\% PI low & 95\% PI high \\
\hline $\begin{array}{l}\text { R1. Droplet size after } 1 \mathrm{~h} \text { of aqueous dilution } \\
\text { of drug-free formulation }(\mathrm{nm})\end{array}$ & 105.8 & 3 & 652 & 677 & 448 & 857 \\
\hline $\begin{array}{l}\text { R2. Droplet size after } 1 \mathrm{~h} \text { of aqueous dilution } \\
\text { of drug-equilibrated formulation }(\mathrm{nm})\end{array}$ & 9.6 & 3 & 48.1 & 43.0 & 32.0 & 64.2 \\
\hline R3. Equilibrium solubility (mg/g) & 0.04 & 6 & 86.6 & 88.0 & 83.0 & 90.7 \\
\hline
\end{tabular}

n: number of replicates; S.D.: standard deviation; PI: prediction interval
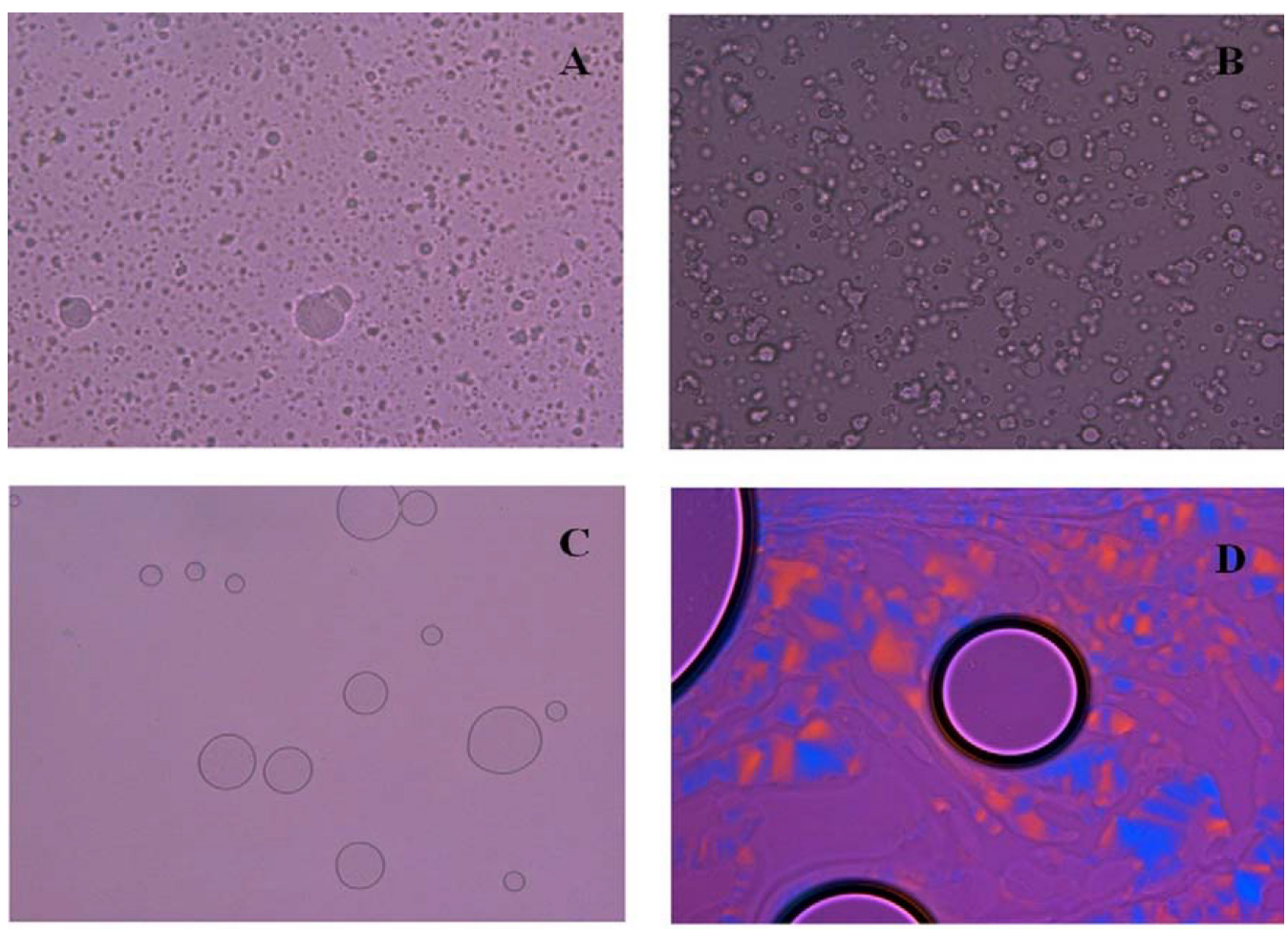

FIGURE 9 - Polarizing microscope images of liquid SNEF showing A: CN-free SNEF/water (70/30, w/w), B: CN-free SNEF/water (50/50, w/w), C: CN-loaded SNEF/water (70/30, w/w), and D: CN-loaded SNEF/water (50/50, w/w).

Abdulaziz City for Science and Technology, Kingdom of Saudi Arabia, Award Number (11NAN1953-02). The authors acknowledge "Kayyali Chair for Pharmaceutical Industries" for hosting the work. In addition, the authors appreciate the professional support from Prof. Adel Sakr.

\section{REFERENCES}

ABDEL-HAMID, M.; SHAHBA, A.; MOHSIN, K.; ALANAZI, F. Ultra-performance liquid chromatography assay for cinnarizine in lipid-based formulations. Asian J. Chem., v.24, p.595-600, 2012.
ATEF, E.; BELMONTE, A.A. Formulation and in vitro and in vivo characterization of a phenytoin self-emulsifying drug delivery system (SEDDS). Eur. J. Pharm. Sci., v.35, p.257-263, 2008.

BAHLOUL, B.; LASSOUED, M.A.; SEGUIN, J.; LAIKUEN, R.; DHOTEL, H.; SFAR, S., MIGNET, N. Selfemulsifying drug delivery system developed by the HLBRSM approach: Characterization by transmission electron microscopy and pharmacokinetic study. Int. J. Pharm., v.487, p.56-63, 2015. 
BAHLOUL, B.; LASSOUED, M.A.; SFAR, S. A novel approach for the development and optimization of self-emulsifying drug delivery system using HLB and response surface methodology: Application to fenofibrate encapsulation. Int. J. Pharm., v.466, p.341-348, 2014.

BAKA, E.; COMER, J.E.A.; TAKÁCS-NOVÁK, K. Study of equilibrium solubility measurement by saturation shake-flask method using hydrochlorothiazide as model compound. J. Pharmac. Biomed., v.46, p.335-341, 2008.

BALAKUMAR, K.; RAGHAVAN, C.V.; SELVAN, N.T.; PRASAD, R.H.; ABDU, S. Self-nanoemulsifying drug delivery system (SNEDDS) of rosuvastatin calcium: design, formulation, bioavailability and pharmacokinetic evaluation. Colloid Surf. B., v.112, p.337-343, 2013.

DAHAN, A.; HOFFMAN, A. Rationalizing the selection of oral lipid based drug delivery systems by an in vitro dynamic lipolysis model for improved oral bioavailability of poorly water soluble drugs. J. Control. Rel., v.129, p.1-10, 2008.

DATE, A.A.; NAGARSENKER, M.S. Design and evaluation of self-nanoemulsifying drug delivery systems (SNEDDS) for cefpodoxime proxetil. Int. J. Pharm., v.329, p.166-172, 2007.

ELNAGGAR, Y.S.R.; EL-MASSIK, M.A.; ABDALLAH, O.Y. Self-nanoemulsifying drug delivery systems of tamoxifen citrate: Design and optimization. Int. J. Pharm., v.380, p.133-141, 2009.

GU, C.H.; RAO, D.; GANDHI, R.B.; HILDEN, J.; RAGHAVAN, $\mathrm{K}$. Using a novel multicompartment dissolution system to predict the effect of gastric $\mathrm{pH}$ on the oral absorption of weak bases with poor intrinsic solubility. J. Pharm. Sci., v.94, p.199-208, 2005.

GUPTA, S.; KESARLA, R.; OMRI, A. Formulation strategies to improve the bioavailability of poorly absorbed drugs with special emphasis on self-emulsifying systems. ISRN Pharm., v.2013, p.16, 2013.

GURSOY, R.N.; BENITA, S. Self-emulsifying drug delivery systems (SEDDS) for improved oral delivery of lipophilic drugs. Biomed. Pharmacother, v.58, p.173-182, 2004.
KANG, B.K.; LEE, J.S.; CHON, S.K.; JEONG, S.Y.; YUK, S.H.; KHANG, G.; LEE, H.B.; CHO, S.H. Development of self-microemulsifying drug delivery systems (SMEDDS) for oral bioavailability enhancement of simvastatin in beagle dogs. Int. J. Pharm., v.274, p.65-73, 2004.

KOMMURU, T.R.; GURLEY, B.; KHAN, M.A.; REDDY, I.K. Self-emulsifying drug delivery systems (SEDDS) of coenzyme Q10: formulation development and bioavailability assessment. Int. J. Pharm., v.212, p.233246, 2001.

KOSSENA, G.A.; CHARMAN, W.N.; BOYD, B.J.; DUNSTAN, D.E.; PORTER, C.J. Probing drug solubilization patterns in the gastrointestinal tract after administration of lipid-based delivery systems: a phase diagram approach. J. Pharm. Sci., v.93, p.332-348, 2004.

LARSEN, A.T.; OGBONNA, A.; ABU-RMAILEH, R.; ABRAHAMSSON, B.; OSTERGAARD, J.; MULLERTZ, A. SNEDDS containing poorly water soluble cinnarizine; development and in vitro characterization of dispersion, digestion and solubilization. Pharmac., v.4, p.641-665, 2012.

LEE, D.R.; PARK, J.S.; BAE, I.H.; LEE, Y.; KIM, B.M. Liquid crystal nanoparticle formulation as an oral drug delivery system for liver-specific distribution. Int. J. Nanomed., v.11, p.853-871, 2016.

LOFTSSON, T.; HREINSDÓTTIR, D.; MÁSSON, M. Evaluation of cyclodextrin solubilization of drugs. Int. J. Pharm., v.302, p.18-28, 2005.

MOHSIN, K.; LONG, M.A.; POUTON, C.W. Design of lipid-based formulations for oral administration of poorly water-soluble drugs: precipitation of drug after dispersion of formulations in aqueous solution. J. Pharm. Sci., v.98, p.3582-3595, 2009.

MOHSIN, K.; POUTON, C.W. The influence of the ratio of lipid to surfactant and the presence of cosolvent on phase behaviour during aqueous dilution of lipid-based drug delivery systems. J. Drug Deliv. Sci. Tec., v.22, p.531-540, 2012.

MUKHERJEE, T.; PLAKOGIANNIS, F.M. Development and oral bioavailability assessment of a supersaturated self-microemulsifying drug delivery system (SMEDDS) of albendazole. J. Pharm. Pharmacol., v.62, p.1112-1120, 2010 . 
NEKKANTI, V.; KARATGI, P.; PRABHU, R.; PILLAI, R. Solid self-microemulsifying formulation for Candesartan cilexetil. AAPS PharmSciTech, v.11, p.9-17, 2010.

NIELSEN, F.S.; GIBAULT, E.; LJUSBERG-WAHREN, H.; ARLETH, L.; PEDERSEN, J.S.; MULLERTZ, A. Characterization of prototype self-nanoemulsifying formulations of lipophilic compounds. J. Pharm. Sci., v.96, p. 876-892, 2007.

PATEL, K.; SARMA, V.; VAVIA, P. Design and evaluation of Lumefantrine - Oleic acid self-nanoemulsifying ionic complex for enhanced dissolution. Daru, v.21, p.27, 2013.

RAGHUVANSHI, S.; PATHAK, K. Recent advances in delivery systems and therapeutics of cinnarizine: a poorly water soluble drug with absorption window in stomach. J. Drug Deliv., v.2014, p.15, 2014.

SHAHBA, A.A.-W.; MOHSIN, K.; ALANAZI, F.K. Novel selfnanoemulsifying drug delivery systems (SNEDDS) for oral delivery of cinnarizine: design, optimization, and in-vitro assessment. AAPS PharmSciTech, v.13, p.967-977, 2012a.
SHAHBA, A.A.; MOHSIN, K.; ALANAZI, F.K. The studies of phase equilibria and efficiency assessment for selfemulsifying lipid-based formulations. AAPS PharmSciTech, v.13, p.522-533, 2012b.

THAKKAR, H.; NANGESH, J.; PARMAR, M.; PATEL, D. Formulation and characterization of lipid-based drug delivery system of raloxifene-microemulsion and self-microemulsifying drug delivery system. J. Pharm. Bioallied. Sci., v.3, p.442-448, 2011.

TOKUMURA, T.; TSUSHIMA, Y.; TATSUISHI, K.; KAYANO, M.; MACHIDA, Y.; NAGAI, T. Enhancement of the oral bioavailability of cinnarizine in oleic acid in beagle dogs. J. Pharm. Sci., v.76, p.286-288, 1987.

Received for publication on $18^{\text {th }}$ April 2016 Accepted for publication on $29^{\text {th }}$ September 2016 
